\begin{tabular}{ccc}
\hline International Journal of Engineering \& Technology, 7 (2.13) (2018) 381-384 & International Journal of Engineering \& Technology \\
SPC & Website: www.sciencepubco.com/index.php/IJET \\
Research Paper & . \\
\hline
\end{tabular}

\title{
Harmonic Meter Design Using Arduino
}

\author{
Azmi Rizki Lubis ${ }^{1}$, A Antoni ${ }^{2}$, Bonar Harahap ${ }^{3}$, Gunawan Tarigan ${ }^{4}$, Jupriah Sarifah ${ }^{4}$ \\ ${ }^{1}$ Department of Electrical Engineering, Faculty of Engineering, Universitas Islam Sumatera Utara, Medan, Indonesia \\ ${ }^{2}$ Department of Informatics Engineering, Faculty of Engineering, Universitas Islam Sumatera Utara, Medan, Indonesia \\ ${ }^{3}$ Department of Industry Engineering, Faculty of Engineering, Universitas Islam Sumatera Utara, Medan, Indonesia \\ ${ }^{4}$ Department of Civil Engineering, Faculty of Engineering, Universitas Islam Sumatera Utara, Medan, Indonesia \\ *Corresponding author E-mail: Azmi.rizki@ft.uisu.ac.id
}

\begin{abstract}
This paper discusses the measurement of harmonic content using arduino which is simulated with proteus software. The components used in this meter harmonic circuit are resistor, capacitor, LCD, microcontroller atmega 328P. Microcontroller works based on voltage source (TR1) and current source (TR2) on proteus software. The voltage and current delivered to the microcontroller will be read and executed according to the program on the microcontroller. The program used in this arduino microcontroller is the $\mathrm{C}$ language program. The results obtained from this study Arduino successfully measure the harmonic content and display the measurement results on the LCD.
\end{abstract}

Keywords: Harmonic Measurement, Arduino, Power Quality

\section{Introduction}

Over the last century, the use of electrical energy has increased exponentially. To overcome this emerging problem then the way that can be taken is to reduce the use of electrical energy in the household sector. This resulted in the need for accurate methods of measuring the use of electrical energy so as to reduce economic losses[1]. The use of non-linear loads in industrial systems continues to evolve which will create new problems of harmonic distortion[2]. Harmonic distortion is something that is often encountered in power systems, computers, and controlled motor speed settings. In telecommunication applications, the use of the harmonic meter is used to determine at the moment when the original frequency is transmitted and then divided into several deviant frequencies. The use of harmonic meters is very important for conducting power quality analysis on electrical power systems and for determining the cause of the problems that arise[3].

Electrical energy is needed by the end user, therefore quality and continuity are inseparable and important things when operating with widely used electronic equipment. Most industrial and business consumers use power electronics equipment that requires a large supply of electrical energy[4]. Increased use of power electronics equipment has been of particular concern as it produces large harmonic content. So that required reactive power compensation on electrical equipment with high sensitivity to avoid disturbance and loss of power[5]. Methods to reduce harmonic content with APF have been proposed in the early 1970s[6].

Power is a critical electrical amount and everything in our reality today relies upon having the ability to keep them running. It is obligatory for a power specialist to know how much the measure of energy a power plant produces and furthermore the utilization by the client over a time of time [7], [8]. It helps in estimation of transmission misfortunes between the age circulation and conveyance purchaser contraption[9]. This estimation helps in control burglary recognition and thus diminishes the transmission misfor- tunes. Estimation of electrical power might be done to quantify electrical parameters of a framework[10]. Contingent on the necessity of precision, time and the idea of the circuit there is a decision for strategy and instrument to be utilized as a part of any given instance of estimation [11]. In the current power utility set up, shoppers are given utilization data just once per month with their bill [12]. The period of time between refreshes about power use is extremely ache for a purchaser to watch a changed conduct's impact on control utilization[13], [14].

A harmonic meter design using arduino introduced in this paper. This paper assist the user to construct homemade Arduino based harmonic meter. The connection diagram is explained in detail. For verification, the harmonic meter is tested in Proteus software.

\section{Harmonic Analysis}

\section{A. Fourier Series}

The trigonometric series for the periodic function $x(t)$ can be expressed by the following equation[15]:

$f(t)=\sum_{n=1}^{\infty}\left(a_{n} \cos \left(\frac{2 \pi n t}{T}\right)+b_{n} \sin \left(\frac{2 \pi n t}{T}\right)+a_{0}\right)$

Equation 1 above is a description of the frequency domain of the periodic function. Component $a_{0}$ is the average value of the function $f(t)$, while $c_{n}$ and $d_{n}$ are the square component series coefficients of the $\mathrm{n}^{\text {th }}$ harmonic. To find the corresponding $\mathrm{n}^{\text {th }}$ harmonic vector the following equation 2 can be used:

$C_{n} \angle \phi_{n}=p_{n}+j q_{n}$

with magnitude 


$$
C_{n}=\sqrt{p_{n}^{2}+q_{n}^{2}}
$$

And to find phase angle can be used :

$\phi_{n}=\tan ^{-1}\left(\frac{q_{n}}{p_{n}}\right)$

With the coefficients $a_{0}, c_{n}$, and $d_{n}$ are respectively

$a_{0}=\frac{1}{T} \int_{0}^{T} f(t) d t$

The fundamental $\mathrm{f}$ value for a period is from 0 to $\mathrm{T}$

$p_{n}=\frac{2}{T} \int_{0}^{T} f(t) \cos n \omega t d t$

$q_{n}=\frac{2}{T} \int_{0}^{T} f(t) \sin n \omega t d t$

Where $\mathrm{n}$ is the harmonic order.

Based on the Fourier series above we get the odd harmonic frequency waveform forming a multiple of fundamental frequencies like the third, fifth, seventh, and so on. In a network of alternating current systems $a_{0}$ will not appear, and if the waveform is perfect or sinusoidal then the existing order is $1^{\text {st }}$ order, ordinary harmonic amplitudes are expressed by:

$C_{h}=\sqrt{p_{n}^{2}+q_{n}^{2}}$

Where $\mathrm{n} \geq 1$ for the value of $\mathrm{C}$ as a function $\mathrm{n}$ is often described in a bar chart and is known as the "Harmonic Spectrum". The Harmonic spectrum is the distribution of all the amplitudes of the harmonic component as its harmonic order function and is illustrated using a histogram. Fig 1 below shows an example of a harmonic spectrum. It can be said that the spectrum is the ratio of current and harmonic frequency voltage to the current and the basic frequency voltage.

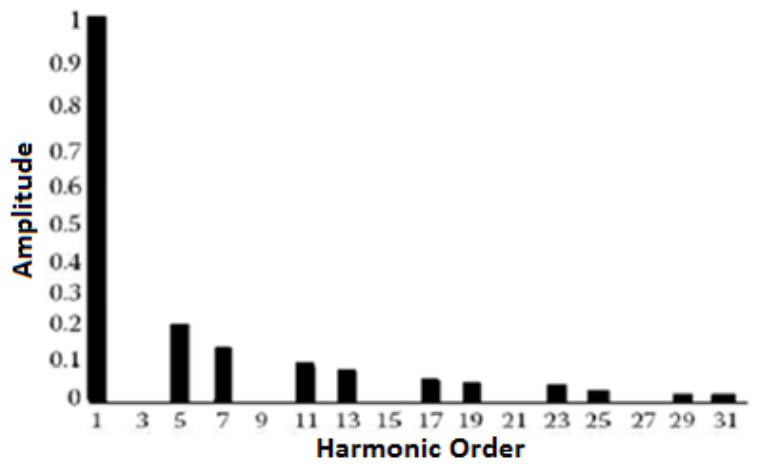

Fig 1: Harmonic Spectrum

\section{B. Fourier Series in Electrical Circuits}

To get steady state response of the circuit to excitation nonsinusoidal periodic is required the use of Fourier series, AC phasor analysis and superposition principle. The necessary step are : (1) express the excitation in the Fourier series, (2) transform the sequence from the time insight form into frequency insights, (3) find response DC and AC component in Fourier series, (4) sum up each response in a superposition.

\section{Complex Form of the Fourier Series}

The geometric interpretation of the relationship between the waveforms in the time domain and the frequency in the plane of the complex can be represented frequency components as rotating vectors. A uniformly rotating vector $A / 2 e^{j \phi}\left(X\left(f_{n}\right)\right)$ has a con- stant magnitude $A / 2$, and a phase angle $\mathrm{f}$, which is time varying according to this formula.

$\phi=2 \pi f T+\theta$

Where $\theta$ is the initial phase angle when $t=0$.A second vector $A / 2 e^{-j \phi}\left(X\left(-f_{n}\right)\right)$ with magnitude $A / 2$ and phase angle $-\theta$ will rotate in the opposite direction to $A / 2 e^{+j \phi}\left(X\left(f_{n}\right)\right)$. The negative frequency is obtained from the level of negative phase angle change. Along the real axis is always the sum of two vectors, the magnitude oscillates between A and -A according to this formula.

$\frac{A}{2} e^{j \phi}+\frac{A}{2} e^{-j \phi}=A \cos \phi$

And finally two half-amplitudes of contra-rotating vector can be represented by each harmonic component of a real-valued signal as shown in Error! Reference source not found., such that.

$X\left(f_{n}\right)=X \times\left(-f_{n}\right)$

Where $X \times\left(-f_{n}\right)$ is the complex conjugate of $X\left(f_{n}\right)$.

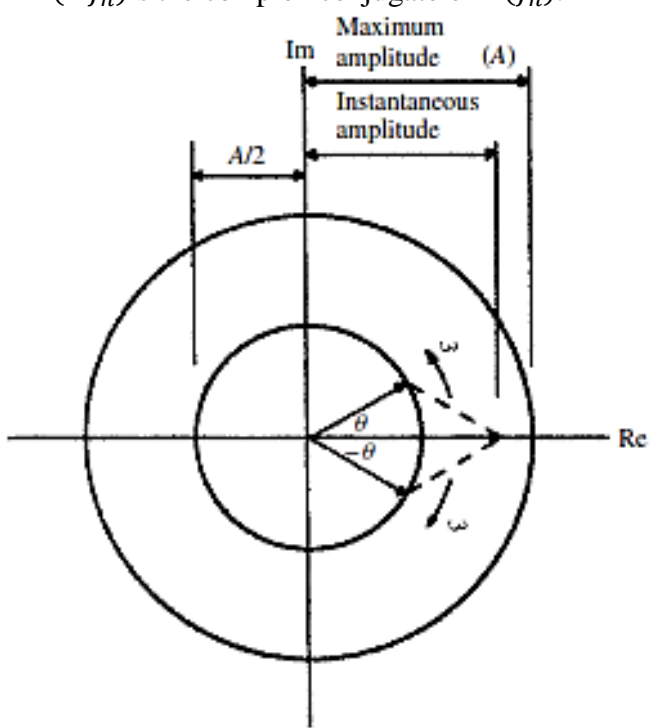

Fig 2: Contra-rotating vector pair producing a varying amplitude (pulsating) vector

\section{Results and Discussion}

This study designs a harmonic meter circuit to measure the third harmonic distortion content using an arduino microcontroller simulated using proteus software. The circuit performs measurements based on current and voltage sources represented by CT and PT. The harmonic distortion measurement is performed based on the third harmonic amplitude ratios to the base frequency.

\section{A. Measures of Harmonic Distortion}

The Fourier series contains the harmonic distortion signals of current and voltage periodically expressed by the following equation[16]:

$i(t)=\sum_{h=1}^{\infty} I_{h} \cos \left(h \omega_{0} t+\varphi_{h}\right)$

\section{B. Current Individual Harmonic Distortion (IHDi)}

Current individual harmonic distortion (IHDi) is the ration between the r.m.s. value of individual harmonics and the r.m.s. value of the fundamentals. The formula is as follows:

$I H D_{i}=\sqrt{\frac{I_{h}}{I_{1}}} \times 100 \%$ 
Where $I_{h}$ is $\mathrm{n}^{\text {th }}$ harmonic current, $I_{1}$ is the fundamental current and $h$ is harmonic order.

\section{Total Harmonic Distortion}

In the electric power system to see harmonic distortion in its fundamental component is termed THD or Total Harmonic Distortion.THD is a voltage waveform corresponding to the harmonic index defined by the root mean square (r.m.s.) of the harmonic expressed in the percentage of the fundamental component, i.e.

$T H D=\sqrt{\frac{\sum_{2}^{n} V_{n}^{2}}{V_{1}}} \times 100 \%$

Where $V_{n}$ is the $\mathrm{n}^{\text {th }}$ harmonic at a single frequency voltage, $V_{1}$ is the fundamental r.m.s voltage and $N$ is the harmonic order. most of the harmonic distortion content measurement ranges from 25 to 50. THD values can be characterized as current distortion levels when low base load currents are low. for a small load the total harmonic distortion greater than the input current is not important, since the harmonic current distortion is relatively small although it is relatively higher than its fundamental frequency.

\section{Discrete Fourier Transform}

Fourier analysis is a very efficient method for analysis and synthesis signal. The method is very closely suited for use on digital computers or for implementation in digital hardware. Discrete Fourier Transform is used for finite signal duration. The tested capacity is the situation where the frequency domain spectrum, as well as the time of the work area, can be obtained separately sections that are compatible with Fourier expressed by the following equation:

$X\left(f_{k}\right)=1 / N \sum_{n=0}^{N-1} x\left(t_{n}\right) e^{-j 2 \pi k n / N}$

And

$x\left(t_{n}\right)=\sum_{k=0}^{N-1} X\left(f_{k}\right) e^{j 2 \pi k n / N}$

Frequency domain spectrum and time domain functions are depicted in Fig 2, with total $\mathrm{N}$ samples per period. The discrete Fourier transform form is a precise digital calculation to evaluate numerically. Consider equation (13) rewritten as:

$X\left(f_{k}\right)=1 / N \sum_{n=0}^{N-1} x\left(t_{n}\right) W^{k n}$

where $W=e^{-j 2 p / N}$. The matrix equation for all frequency components in equation (9) is as follows :

\begin{tabular}{|c|c|c|c|}
\hline $\begin{array}{l}X\left(f_{0}\right) \\
X(f)\end{array}$ & & $\begin{array}{llllll}1 & 1 & \ldots & 1 & \ldots\end{array}$ & $x\left(t_{0}\right)$ \\
\hline$X\left(f_{1}\right)$ & & $1 \quad W \ldots . W^{k} . . W^{N-1}$ & $x\left(t_{1}\right)$ \\
\hline • & & $\cdot \cdot$ & . \\
\hline - & 1 & $\cdot \cdot$ & 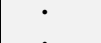 \\
\hline$X\left(f_{k}\right)$ & $-\bar{N}$ & $1 W^{k} \ldots . W^{k^{2}} . W^{k(N-1)}$ & $x\left(t_{k}\right)$ \\
\hline$X\left(\dot{f_{N-1}}\right)$ & & $\dot{1} W^{N-1} \ldots W^{(N-1) k} \ldots W^{(N-1)^{2}}$ & $x\left(t_{N-1}\right)$ \\
\hline
\end{tabular}
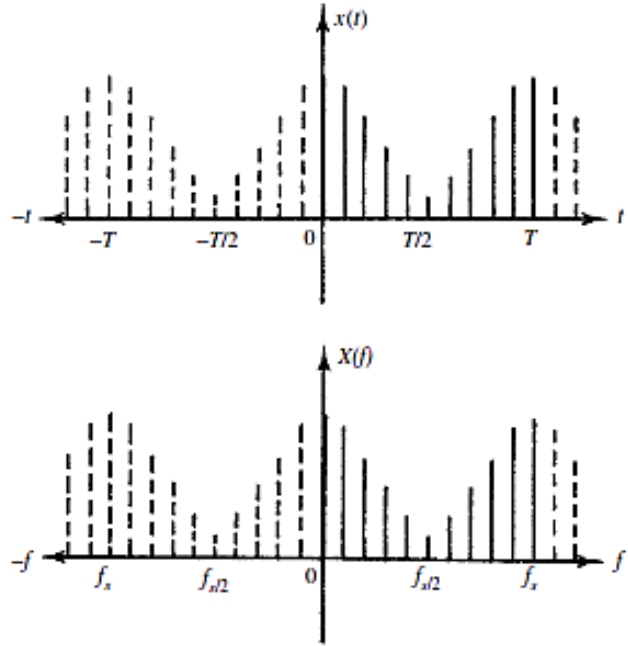

Fig 2: Discrete time- and frequency-domain function

Or in a condensed form

$\left[X\left(f_{k}\right)=1 / N\left[W^{k n}\right]\left[x\left(t_{n}\right)\right]\right]$

In this equation, $\left[X\left(f_{k}\right)\right]$ is a vector of $\mathrm{N}$ components represented by the frequency domain function, while $\left[x\left(t_{n}\right)\right]$ vector of component $\mathrm{N}$ samples is represented by time domain function. To calculate the total elaborate product $N^{2}$ required a frequency component $\mathrm{N}$ of sample $\mathrm{N}$ which is implemented in the above form. Each element in the matrix $\left[W^{k n}\right]$ represents the unit vector with clockwise rotation $2 n \pi / N(n=0,1,2, \ldots,(N-1))$ introduced between consecutive components. All these values are the same depending on the value of $\mathrm{N}$.

\section{Simulation Result}

Current harmonic measurements are simulated by using proteus software, harmonic meter circuit which is simulated using arduino microcontroller. The meter harmonic circuit works based on simulated voltage and current supply with transformer 1 (TR1) replacement component to supply voltage and transformer 2 (TR2) to supply the current. Arduino microcontroller is programmed to display the $3^{\text {rd }}$ order individual harmonic current, voltage, current and power factor then displayed in Liquid Crystal Display (LCD). Output TR1 is connected to a $470 \mathrm{k}$ ohm resistor component as an analog input voltage used as a bias voltage regulator. In addition there are two resistor components respectively worth $100 \mathrm{k}$ and $10 \mathrm{k}$ as a voltage divider of 2.5 volts DC to arduino and 10uf capacitor components to pass the high frequency components by reducing the impedance. The TR2 output is connected to two.

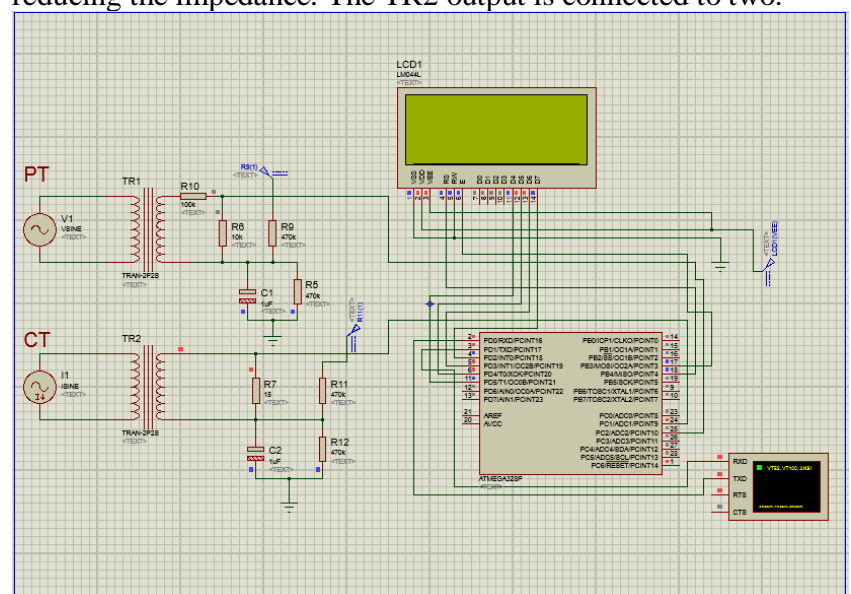

Fig 4: Harmonic Meter Circuit 
470k ohm resistor components as a current analogue input used as a bias current regulator. The $15 \mathrm{ohm}$ resistor component serves to serve the load. And the 10uf capacitor component to pass the high frequency components by reducing the impedance. The harmonic meter circuit is indicated in fig 4 .

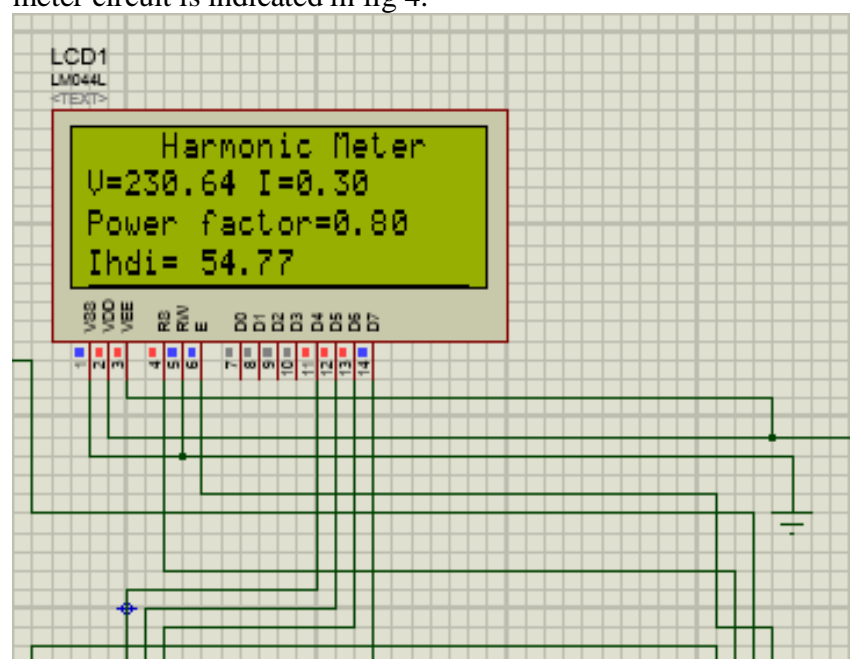

Fig 5: Simulation Result

\section{Conclusion}

From the research that has been done then arduino managed to show the measurement of harmonic content of $3^{\text {rd }}$ order current, voltage, current and power factor displayed by LCD. The programming language used is $\mathrm{C}$ language, this programming language tends to be widely used by programmers because of its more practical use. For the next research it is advisable to design a series of harmonic meters using wireless.

\section{References}

[1] P. D. V. and S. P. M. Srividyadevi P., "Measurement of Power and Energy Using Arduino,” Res. J. Eng. Sci., vol. 2, no. 10, pp. 10-15, 2013.

[2] A. R. Lubis, "Efektivitas Penggunaan Filter Pasif LC dalam Mengurangi Harmonik Arus," J. Electr. Technol., vol. 2, no. 3, pp. $1-8,2017$.

[3] D. A. Jaipreet Kaur Bhatti, "Harmonic Detection using Microcontroller," Int. J. Comput. Technol. Electron. Eng., vol. 2, no. 3, pp. 106-109, 2012.

[4] U. P. Yagnik and M. D. Solanki, "Comparison of L, LC LCL filter for grid connected converter," in 2017 International Conference on Trends in Electronics and Informatics (ICEI), 2017, pp. 455-458.

[5] E. Özer, "A Real-Time Harmonic Detection Method for SinglePhase Active Power Filters," Int. J. Appl. Math. Electron. Comput., vol. 4, p. 87, 2016

[6] H. Sasaki and T. Machida, "A New Method to Eliminate AC Harmonic Currents by Magnetic Flux CompensationConsiderations on Basic Design," IEEE Trans. Power Appar. Syst., vol. PAS-90, no. 5, pp. 2009-2019, 1971.

[7] A. Cataliotti, V. Cosentino, D. Di Cara, A. Lipari, S. Nuccio, and C. Spataro, "A PC-based wattmeter for high accuracy power measurements," in 2010 IEEE Instrumentation Measurement Technology Conference Proceedings, 2010, pp. 1453-1458.

[8] M. Misakian, "Measurement of electrical parameters near AC and DC power lines," in 1988. IMTC-88. 5th IEEE Instrumentation and Measurement Technology Conference, 1988, p. 114-

[9] V. Kuznetsov and A. Kuznetsov, "Measurement of power quality factors in electrical networks," in Proceedings of 20th Biennial Conference on Precision Electromagnetic Measurements, 1996, p. SUPL33.

[10] IEEE Master Test Guide for Electrical Measurements in Power Circuits. IEEE Power an Energy Society, 1989.

[11] J. Driesen et al., "Development of a measurement system for power quantities in electrical energy distribution systems," in IMTC/2002. Proceedings of the 19th IEEE Instrumentation and Measurement Technology Conference (IEEE Cat. No.00CH37276), 2002, vol. 2, pp. $1625-1630$ vol.2.
[12] A. K. Sawhney and P. Sawhney, A Course in Electrical and Electronic Measurements and Instrumentation. Rai, 1996.

[13] T. E. D. Liacco, "Real-time computer control of power systems," Proc. IEEE, vol. 62, no. 7, pp. 884-891, 1974.

[14] D. A. Katsaprakakis, D. G. Christakis, A. Zervos, and S. Voutsinas, "A Power-Quality Measure," IEEE Trans. Power Deliv., vol. 23, no. 2, pp. 553-561, 2008.

[15] J. Arrillaga and N. R. Watson, Power System Harmonics. Wiley, 2004.

[16] G. J. Wakileh, Power Systems Harmonics: Fundamentals, Analysis and Filter Design. Springer Berlin Heidelberg, 2010. 